\title{
Motor performance, functional status and quality of life in children with dyslexia
}

\author{
Sebahat Yaprak Çetin ${ }^{1}$, Ali Kitiş ${ }^{2}$ Figen Şen Kösem ${ }^{3}$ \\ ${ }^{1}$ Department of Physical Therapy and Rehabilitation, Cyprus International University Faculty of Health Sciences, Nicosia, North \\ Cyprus \\ ${ }^{2}$ Department of Physical Therapy and Rehabilitation Pamukkale University School of Medicine, Denizli, Turkey \\ ${ }^{3}$ Child and Adolescent Psychiatrist, Dr. Figen Şen Kösem Private Clinic, Denizli, Turkey
}

DOI: $10.18621 /$ eurj.365934

\begin{abstract}
Objectives: The purpose of this study was to assess motor performance, functional status and quality of life in children with dyslexia by the Diagnostic and Statistical Manual of Mental Disorders Turkish version (DSMIV-TR), and compare the outcome with typically developing children.

Methods: This study includes 28 dyslexic and 28 typically developing children at the age of 7 to 12 years. Motor abilities and proficiencies were evaluated with the short form of the second version of the Bruininks Oseretsky Test of Motor Proficiency (BOTMP 2-SF). The Functional Independence Measure for Children (WeeFIM) was used to measure functional status. Quality of life in the children evaluated with the Pediatric Quality of Life Inventory (PedsQL).

Results: There was a significant difference found between the results of the two groups on motor abilities, functional status and quality of life $(p<0.05)$.

Conclusions: We think that, according to the obtained results, it is important to assess in detail and plan rehabilitation programs such as education at daily living activities in order to increase the quality of life in dyslexic children who were diagnosed in terms of motor performance.
\end{abstract}

Keywords: dyslexia, motor performance dysfunction, activities of daily living, quality of life

Received: December 14, 2017; Accepted: January 10, 2018; Published Online: February 10, 2018

D yslexia is a neurobiological origin of learning disability called developmental dysfunction defined by Diagnostic and Statistical Manual of Mental Disorders (DSM-IV) [1]. Even though children with dylexia have difficulties in reading, writing and spelling, the intelligence levels are normal or above. Prevalence of dyslexia in schools of the western world is reported to be $5 \%$ to $10 \%$; it also occurs four to five times more often in boys than girls $[2,3]$. Learning disabilities which contain dyslexia have various negative effects on a person's life, especially when it comes to students since it leads to deficiencies in their academic learning, a low self-esteem, physical and psychological problems, and behavioral problems [4]. Literature's main focus has been on the school-related problems such as deficiency in reading skills and academic performance because there is a relationship between dyslexia and academic performance. However, recent studies have shown that this population also suffers deficits in motor performance, including bilateral hand coordination, general hand dexterity, and fine motor dexterity [5-7]. The

Address for correspondence: Sebahat Yaprak Çetin, MD., Cyprus International University Faculty of Health Sciences, Department of Physical Therapy and Rehabilitation Nicosia, North Cyprus

E-mail:fzt_s.yaprakulgen@hotmail.com 
relationship between dyslexia and alterations in motor coordination is important during assessment and diagnosis $[8,9]$.

Specific learning disorders including dyslexia children are faced with many limitations when it comes to physical activities including personal care, their schoolwork, and social activities they do with friends because they have deficiencies in motor skills [4]. However, early identification of these problems and using different measures to improve the dyslexic child's level of participation may help to solve the physical and psychological problems.

Children with specific learning disorders who have difficulty in motor skills may also encounter difficulties in their daily living activities [1]. Though there were studies on motor skills and quality of life in children with dylexia in the literature $[4,5,7]$, there were no studies evaluating the activities of daily living in this children. Studies generally examined children with specific learning disorders and not only children with dylexia. Furthermore, there has not yet been any of these kind of studies done in Turkey. The purpose of this study was to assess motor performance, functional status, and quality of life in children with dyslexia who have diagnosed by using Turkish version of DSM IV and compare the outcomes with typically developing children.

\section{METHODS}

This study includes 28 dyslexic and 28 typically developing children with ages ranging from 7 to 12 years. Inclusion criteria for children with dyslexia: diagnosis of dyslexia, to attend elementary school together with a full scale Wechsler Intelligence Scale for Children-Revised (WISC-R) IQ of at least 85 at diagnosis; children whose visual, hearing, physical and mental handicap with the diagnosis of dyslexia were excluded [10]. The dyslexic children who were included in the study have been studying at an elementary school affiliated with the Denizli Provincial Directorate of National Education and also have been getting special education and rehabilitation in a center affiliated with the Denizli Provincial Directorate of National Education. The typically developing children were in the same age range as dyslexic children included in the study with no visual, hearing, physical, mental and special learning disabilities. The typically developing children were randomly chosen among the students studying at elementary school, which is affiliated to the Denizli Provincial Directorate of National Education. The study protocol was approved by The Ethics Committee of Pamukkale University (number 60116787-020/54981). An informed consent form has been signed to the parents of the children.

Motor abilities and proficiencies were evaluated using The short form of the second version of the Bruininks Oseretsky Test of Motor Proficiency (BOTMP 2-SF). This scale was developed by Dr. Robert H. Bruininks [11]. BOTMP 2-SF is able to measure the motor abilities of children from 4 years old until 14.5 years old. The scale was tested for validity and reliability, and its validity and reliability were found to be sufficient. It can be used a screening tool to identify children with motor deficits who may benefit from intervention activities and takes less time to administer. BOTMP 2-SF comprises 8 subtests: Fine motor precision, fine motor integration, manual dexterity, bilateral coordination, balance running speed and agility, upper limb coordination, and strength [11].

The Functional Independence Measure for Children (WeeFIM) was used to measure functional status. This scale contains 18 items, taking minimum amount of time, and has minimum number of questions and provides information about selfcare, sphincter control, mobility, locomotion, communication, and social cognition. Each sub-item of the WeeFIM is scored using a scale that ranges from 1 to 7; 7: fully independent (timely, safety), 6: modified independent (device), 5: supervision, 4: minimal assistance $($ subject $=75 \%+$ ), 3: moderate assistance ( subject $=50 \%+$ ), 2: maximal assistance $($ subject $=25 \%+)$, and $1:$ total assistance $($ subject $=$ $0 \%+)$. The total score is calculated as minimum being 18 and maximum 126 points [12]. WeeFIM was first used to determine the functional status of congenital malformations between 6 months and 7 years of age, and validity and reliability of these disease groups have been demonstrated [13]. For individuals with neurodevelopmental impairment such as special learning disorders, it is used between 6 months and 21 
years [14].

Quality of life of the children was evaluated with the Pediatric Quality of Life Inventory (PedsQL). PedsQL was developed by Varni et al. [15] to measure the health-related quality of life for children ages between 2 and 18 years and adolescents. This scale uses a Likert-type scale and asks questions for a child or adolescent of what has happened in the last month. The items are scored between 0 and 100. The answers were never marked as 100 and rarely marked 75; sometimes it was marked 50, at times marked 25, and almost always 0 . The total score was calculated by dividing the number of items by the sum of the points received from all items.

\section{Statistical Analysis}

The statistical analysis was done by using 16.0 version of Statistical Package for Social Sciences (SPSS) which uses Windows operating system. For the descriptive data average of standard deviation, frequency, and percentage was used. Since the parameters did not show a normal distribution, nonparametric analysis (Mann-Whitney $U$ ) was used for compare the groups. In statistics $p$ value was accepted as 0.05 significance level.

\section{RESULTS}

The dyslexic children consisted of 21 boys and 7 girls; and the typically developing children were 11 girls and 17 boys. The average age of the dyslexic children was $9.14 \pm 1.48$ years; the average age of the typically developing children was $9.50 \pm 1.26$ years (Table 1).

When dyslexic children were compared with typically developing children, there was a significant difference between the two groups in all subtests of BOT 2-SF and the total score $(p<0.05)$ (Table 2). According to WeeFIM test results, there was a significant difference between the two groups in selfcare, social cognition, and total score $(p<0.05)$ (Table $2)$. There was a significant difference between the two groups in all parts of the PedsQL test and in the total score $(p<0.05)$ (Table 3).

Table 1. Demografic data in dyslexic and typically developing children

\begin{tabular}{lcc}
\hline & $\begin{array}{c}\text { Dyslexic children } \\
(\mathbf{n}=\mathbf{2 8})\end{array}$ & $\begin{array}{c}\text { Typically developing children } \\
(\mathbf{n}=\mathbf{2 8})\end{array}$ \\
\hline Age (years) & $9.14 \pm 1.48$ & $9.50 \pm 1.26$ \\
Gender & & \\
$\quad$ Boys, n (\%) & $21(75)$ & $17(60.7)$ \\
Girls, n $(\%)$ & $7(25)$ & $11(39.3)$ \\
\hline
\end{tabular}

Data are shown as mean \pm standard deviation or number (percent)

Table 2. Comparison of motor abilities and proficiencies in dyslexic and typically developing children

\begin{tabular}{lccc}
\hline BOTMP 2-SF subtests & Dyslexic children & $\begin{array}{c}\text { Typically developing } \\
\text { children }\end{array}$ & $\boldsymbol{p}$ \\
\hline Fine motor precision & $6.89 \pm 4.54$ & $10.92 \pm 2.12$ & $0.00^{*}$ \\
Fine motor integration & $6.85 \pm 2.22$ & $8.64 \pm 1.76$ & $0.00^{*}$ \\
Manual dexterity & $5.55 \pm 1.46$ & $5.50 \pm 1.47$ & $0.00^{*}$ \\
Bilateral coordination & $0.92 \pm 0.89$ & $7.00 \pm 0.00$ & $0.00^{*}$ \\
Balance & $1.50 \pm 0.74$ & $8.00 \pm 0.00$ & $0.00^{*}$ \\
Running speed and agility & $7.14 \pm 6.81$ & $9.64 \pm 1.06$ & $0.03^{*}$ \\
Upper-Limb coordination & $1.21 \pm 0.73$ & $10.82 \pm 2.07$ & $0.00^{*}$ \\
Strength & $7.32 \pm 4.65$ & $13.17 \pm 3.78$ & $0.00^{*}$ \\
Total & $38.96 \pm 15.35$ & $73.35 \pm 3.87$ & $0.00^{*}$ \\
\hline
\end{tabular}

Data are shown as mean \pm standard deviation. BOTMP-2 SF $=$ Short Form of the second version of the Bruininks Oseretsky Test of Motor Proficiency, *Mann Whitney U test $(p<0.05)$ 
Table 3. Comparison of functional status and quality of life of dyslexic and typically developing children

\begin{tabular}{lccc}
\hline & Dyslexic children & $\begin{array}{c}\text { Typically developing } \\
\text { children }\end{array}$ & $\boldsymbol{p}$ \\
\hline Self-care & $41.00 \pm 1.69$ & $42.00 \pm 0.00$ & $0.00^{*}$ \\
Sphincter control & $14.00 \pm 0.00$ & $14.00 \pm 0.00$ & 1.00 \\
Transfers & $21.00 \pm 0.00$ & $21.00 \pm 0.00$ & 1.00 \\
Locomotion & $14.00 \pm 0.00$ & $14.00 \pm 0.00$ & 1.00 \\
Communication & $14.00 \pm 0.00$ & $14.00 \pm 0.00$ & 1.00 \\
Social cognition & $13.14 \pm 3.75$ & $20.42 \pm 2.11$ & $0.00^{*}$ \\
WeeFIM total & $117.28 \pm 3.83$ & $125.32 \pm 2.58$ & $0.00^{*}$ \\
Physical & $85.71 \pm 5.60$ & $91.96 \pm 3.84$ & $0.00^{*}$ \\
Emotional & $81.96 \pm 7.85$ & $88.21 \pm 11.15$ & $0.01^{*}$ \\
Social & $36.60 \pm 24.11$ & $96.25 \pm 4.43$ & $0.00^{*}$ \\
School & $30.00 \pm 16.44$ & $72.40 \pm 11.71$ & $0.00^{*}$ \\
PedsQL total & $61.46 \pm 7.48$ & $87.80 \pm 6.20$ & $0.00^{*}$ \\
\hline Data are
\end{tabular}

Data are shown as mean \pm standard deviation. WeeFIM $=$ Functional Independence Measure for Children, PedsQL $=$ Pediatric Quality of Life Inventory, *Mann Whitney U test $(p<0.05)$

\section{DISCUSSION}

The conclusion of this study is that the motor performance consisting of fine motor precision and integration, manual dexterity, bilateral coordination, balance, running speed and agility, and upper limb coordination in dyslexic children was found to be at lower levels than the motor performance of typically developing children. Also, the functional status (selfcare and social cognition subsections) and quality of life of dyslexic children was found to be worse than in the typically developing children.

Many studies comparing the motor performance of dyslexic children with typically developing children could be found in the literature. In Miyahara's study [16] the gross motor skills of children with learning disorders and typically developing children were compared, by using the subtests running speed and agility, balance, bilateral coordination, strength, and upper limb coordination of the BOTMP. On the subtests running speed and agility, bilateral coordination and strength significant differences were found between the two groups. In another study dyslexic children were compared with children with good academic performance at school in motor skills by using all subtests of the BOTMP. The result of this study showed a lower performance for dyslexic children in all subtests when compared to other children. Although there is no significant statistical difference found between the two groups in the motor skills subtests, there is a significant difference that is seen in gripping, cutting, drawing, and writing especially in the area of accuracy and hand dexterity [7]. Several studies have compared dyslexic children with typically developing children in terms of balance skills and dyslexic children were worse than typically developing children $[5,17,18]$.

In our study, we found that children with dyslexia had lower scores than typically developing children in all subtests of BOTMP 2-SF. The conclusion that was drawn regarding the upper extremity coordination suggests that the difference between the two groups is a clinically significant difference. The evidence of deficiencies in motor skills cannot be interpreted only with the BOTMP 2-SF test because the difficulties in motor skills are heterogeneous and these difficulties include balance, coordination, and motion control and all are related to poor cerebellar function [19]. Nicolson et al. [20] suggest that reading and writing problems that come from motor control may not alone be only caused by impaired functioning of the cerebellum in dyslexia. They think that cerebellar dysfunction limits motor control and coordination as well as cognitive skills such as reading. Besides, Berninger et al. [21] stated that reading and writing require proper muscle activation for sound production, control of tongue, sensory motor tasks, and hand skills. In this case, dyslexia is closely related to sensory integration [21]. Sensory integration training should be given to dyslexic whose weaknesses is in 
academic skills such as reading and writing and for motor problems in the occupational therapy.

According to the additional criteria specified in the DSM IV, motor difficulties have a negative impact on academic achievement and daily living activities [22]. The daily life of individuals with learning disabilities might be affected by neurobiological problems like poor memory, lack of judgment, and problem-solving potential [23]. Accordingly, in their childhood they show poor performance at school, and as adults they face problems when it comes to being able to function professionally [24]. In our study, children with dyslexia received lower scores in self-care and social cognition subscales, and the total scores in the assessment of functional status were also lower than in typically developing children. The fine motor skills and upper extremity coordination are important when it comes to self-care and in performing everyday activities. Dyslexia is also part of the sensorymotor integration that occurs in the majority of our daily life. In this context, our study found that the inadequacies of children with dyslexia in daily activities and in motor skills were perceived by parents, but they were not interviewed and asked about whether they were getting training in daily living activities. According to our findings, we believe that occupational therapy for the difficulties in daily living activities that students meet in school and at home should be supported by legal and standardized educational programs. In addition, individual and group activities may be useful in getting rid of social communication difficulties that they experience in school. Future studies will contribute to the literature by assessing the daily living activity difficulties that are caused by the insufficient motor performance of children with dyslexia such as dyslexia by various methods.

A learning disorder is a lifelong condition. The impact on society is quite meaningful. Children with special learning disorders, like dyslexia, are negatively affected in school, social interaction, and relationships with their family and peers. The social relationships and emotional functionality of an individual might become affected because of cognitive function deficits. Karande et al. [25] have stated a lower quality of life status in children with newly diagnosed specific learning disorders. The quality of life of children studying in primary education in Austria wasevaluated by PedsQL, and the result showed a lower quality of life for children who were diagnosed with a disorder as dyslexia [26]. In recent years, there was no difference between the groups in a study that evaluated the quality of life in children with reading disorders and non-reading disorders [27]. In our study, PedsQL was used to assess quality of life and children with dyslexia and those children were found to have lower scores. Insufficient motor performance causes dependence in activities of daily living and poor quality of life status in children with dyslexia.

There is a need for many more studies in order to identify possible causes and underlying mechanisms of dyslexia. As Stoodley and Stein think, the dyslexia sensorymotor relationship can shed some light on these issues [28].

\section{The Limitations of the Study}

One of the main limitations of this study is that insufficient number of children with dyslexia participate in this study. Additionally, comparing different age groups that have dyslexia could help the research to achieve a more detailed picture of the effects on motor skills. Another limitation of this study is the use of cross-sectional data.

\section{CONCLUSION}

We think that the obtained results need to be assessed in detail in order to help plan occupational therapy and sensorimotor integration training programs for daily living activities in order to increase the quality of life for dyslexic children who were diagnosed in terms of motor performance. In addition to this literature, there is a need for more studies in order to evaluate the motor performance, functional status and quality of life of dyslexic children.

\section{Conflict of interest}

The authors disclosed no conflict of interest during the preparation or publication of this manuscript.

\section{Financing}

The authors disclosed that they did not receive any grant during conduction or writing of this study.

\section{Acknowledgements}

This article was presented as a poster at I. 


\section{International Participated Ergotherapy and Rehabilitation Congress, on May $30^{\text {th }}-$ June $1^{\text {st }}, 2013$, Ankara, Turkey}

\section{REFERENCES}

[1] American Psychiatric Association, Diagnostic and statistical manual of mental disorders Criteria DSM-4, American Psychiatric Association Washington, DC, 2005.

[2] Badian NA. Reading disability in an epidemiological context: incidence and enviromental correlates. J Learn Disabil 1984;17:129-36.

[3] Siegel LS. Perspectives on dyslexia. Peadiatr 2006;11:581-7.

[4] Kheyroddin B. The comparison of motor skills of dyslexic and nondyslexic students. Med J Tabriz University of Med Sci 2007;28:710 .

[5] Getchell N, Pabreja P, Neeld K, Carrio V. Comparing children with and without dylexia on the movement assessment battery for children and the test of gross motor development. Percep Motor Skill 2007;105:207-14.

[6] Wolff PH, Michel GF, Ovrut MR. Rate and timing precision of motor coordination in developmental dyslexia. Dev Psychol 1990;26:82-9.

[7] Okudo PMM, Ramos FG, Santos LCA, Padula NAMR, Kirby A, Capellini SA. Motor profile of students with dyslexia. Psychol Res 2014;4:31-39.

[8] Nicolson R, Fawcett A. Dyslexia, dysgraphia, procedural learning and the cerebellum. Cortex 2011;47:117-27.

[9] Pieters S, Desoete A, Van Waelvelde H, Vanderwalsmen R, Roeyers $\mathrm{H}$. Mathematical problems in children with developmental coordination disorder. Res Dev Disabil 2012;13:1128-35.

[10] Savaşır I, Şahin N. Wechsler çocuklar için zeka ölcegi (WISC-R) uygulama kitapçığı. Türk Psikologlar Dernegi, Ankara, 1995.

[11] Bruininks R, Bruininks B. Bruininks-Oseretsky test of motor proficiency (2nd ed.). Minneapolis, MN: NCS Pearson; 2005.

[12] Msall ME, DiGaudio K, Rogers BT, LaForest S, Catanzaro NL, Campbell J, et al. The Functional Independence Measure for Children (WeeFIM). Conceptual basis and pilot use in children with developmental disabilities. Clin Pediatr (Phila) 1994;33:421-30.

[13] Msall ME, DiGaudio KM, Duffy LC. Use of functional assessment in children with developmental disabilities. Phys Med Rehabil Clin North Am 1993;4:517-27.

[14] Gurucharri L. Measuring developmental and functional status in children with disabilities. Pediatr Phys Ther 2003;15:43-5.

[15] Varni JW, Seid M, Rode CA. The PedsQL: measurement model for the pediatric quality of life inventory. Med Care 1999;37:126-39.

[16] Miyahara M. Subtypes of students with learning disabilities based upon gross motor functions. Adapt Phys Activ Q 1994;11:368-82.

[17] Chaix Y, Albaret JM, Brassarda C, Cheureta E, Castelnaua P, Benesteaua $\mathrm{J}$, et al. Motor impairment in dyslexia: the influence of attention disorders. Eur J Peadiatr Neurol 2007;11:368-74.

[18] Nicolson RI, Fawcett AJ. Comparison of deficits in cognitive and motor skills among children with dyslexia. Ann Dyslexia 1994;44:14764.

[19] O'Hare A, Khalid S. The association of abnormal cerebellar function in children with developmental coordination disorder and reading difficulties. Dyslexia 2002;8:234-48.

[20] Nicolson RI, Fawcett AJ, Dean P. Developmental dyslexia: the cerebellar deficit hypothesis. Trends Neurosci 2001;24:508-11.

[21] Berninger VW, Nielsen KH, Abbott RD, Vinjsman E, Raskind W. Writing problems in developmental dyslexia: under-recognized and under-treated. J Sch Psychol 2008;46:1-21.

[22] Visser, J. Developmental coordination disorder: a review of research on subtypes and comorbidities. Human Mov Sci 2003;22:479-93.

[23] Tsatsanis KD, Fuerst DR, Rourke BP. Psychosocial dimensions of learning disabilities: External validation and relationship with age and academic functioning. J Learn Disabil 1997;30:490-502.

[24] Silver CH, Ruff RM, Iverson GL, Barth JT, Broshek DK, Bush SS, et al. Learning disabilities: the need for neuropsychological evaluation. Arch Clin Neuropsychol 2008;23:217-9.

[25] Karande S, Bhosrekar K, Kulkarni M, Thakker A. Health-related quality of life of children with newly diagnosed specific learning disability. J Tropic Pediatr 2008;55:161-9.

[26] Felder-Puig R, Baumgartner M, Topf R, Gadner H, Formann AK. Health related quality of life in Austrian elementary school children. Med Care 2008;46:432-9.

[27] Balazs J, Miklosi M, Toro KT, Nagy-Varga D. Reading disabilities and quality of life based on both self- and parent- reports: importance of gender differences. Front Psychol 2016;15:1942.

[28] Stoodley CJ, Stein JF. The cerebellum and dyslexia. Cortex 2011;47:101-16 